\title{
Initial Management of Burns
}

\author{
Col BB Dogra
}

\begin{abstract}
Burns is a preventable tragedy, which is unfortunately still common in India. The possibility of disfigurement, death and emotional trauma as a result of burns is a shattering experience to the victim as well as his/her family. Proper initial management can salvage many such unfortunate victims. Burns patients require close monitoring, barrier nursing and sympathetic attitude of medical and paramedical staff in a burns ICU to have a reasonable chance of survival.
\end{abstract}

MJAFI 2004; 60 : 277-280

Key Words : Burns; Inhalation injury; Resuscitation; Wound management

\section{Introduction}

$\mathrm{T}_{\mathrm{t}}$ The incidence of burn injury has declined steadily over the past several decades in the United States and in some other developed countries. However, incidence is still on the higher side in our country because of illiteracy prevalent in rural India and its social fabric, where the practice of bride burning is still reported in the newspapers almost everyday. Despite this declining incidence in western countries, about 1.25 million persons are still treated for burns annually in the United States, and 50,000 are hospitalized each year for the treatment of burns [1]. Although exact figures are not available from our country, each year more than 2.5 million people experience burn injuries in United States. Approximately 1 million of these incidents involve children, and $60 \%$ occur in the home. Burn injuries not only represent a threat to life, but, since burns affect primarily the young, cost in terms of loss of lives and working years is significant[2]. Burns are however preventable, and prevention is a cost-effective strategy for educators to employ.

Bride burning is a stigma to our society and all right thinking people should ensure its eradication from our society. Secondly in our villages, there still exists the practice of open flame (chulha) for cooking. Use of free flowing garments like a saree made from synthetic material makes the setting even more dangerous for accidents, which can be easily avoided by using cotton dresses and not keeping the open flame at ground level in their kitchens.

\section{Burn Shock}

\section{Pathophysiology}

After a burn, fluid accumulates rapidly in the wound and, to a lesser extent, in unburned tissues. If the burns involve at least 15 to 20 percent of the body - surface area, hypovolemic shock will develop unless there is effective and rapid intervention. Edema formation is most rapid in the first 6 to 8 hours after injury but continues for 18 to 24 hours [2]. Inflammatory mediators are released locally, partly from activated platelets, macrophages, and leukocytes and contribute to local and systemic hyper permeability of the microcirculation [3] as depicted in Fig 1.

Histologically, gaps appear in the venular and capillary endothelium. Regional blood flow increases and is accompanied by an early increase in capillary pressure. Erythrocytes also are invariably extravasated, but substantial early loss of blood is rare, and transfusion is not required or desirable during first 48 hours. Major burns precipitate a systemic inflammatory response that if overly prolonged or exaggerated leads to organ dysfunction, sepsis, or both. The local mediators listed above appear within minutes to hours after the injury. Among the systemic mediators, plasma levels of interleukin-1, 2 and 8 are elevated very early. Increases in the level of interleukin- 6 occur with sepsis. Transient elevations of tumour necrosis factor are associated with a poor prognosis. Interferon levels tend to peak about 10 days after the burn.

Many factors in addition to the extent of the burn, especially age, determine the severity of injury. A patient sustaining burns over 20 percent of the body-surface area has got a 30 percent risk of mortality in a 70 year old patient but is not lethal in a 20 year old patient.

\section{Fluid Resuscitation in burns}

Sodium -salt solutions (crystalloids) are the essential component of fluid resuscitation. Lactated Ringer's solution has been the most widely used of these solutions. 


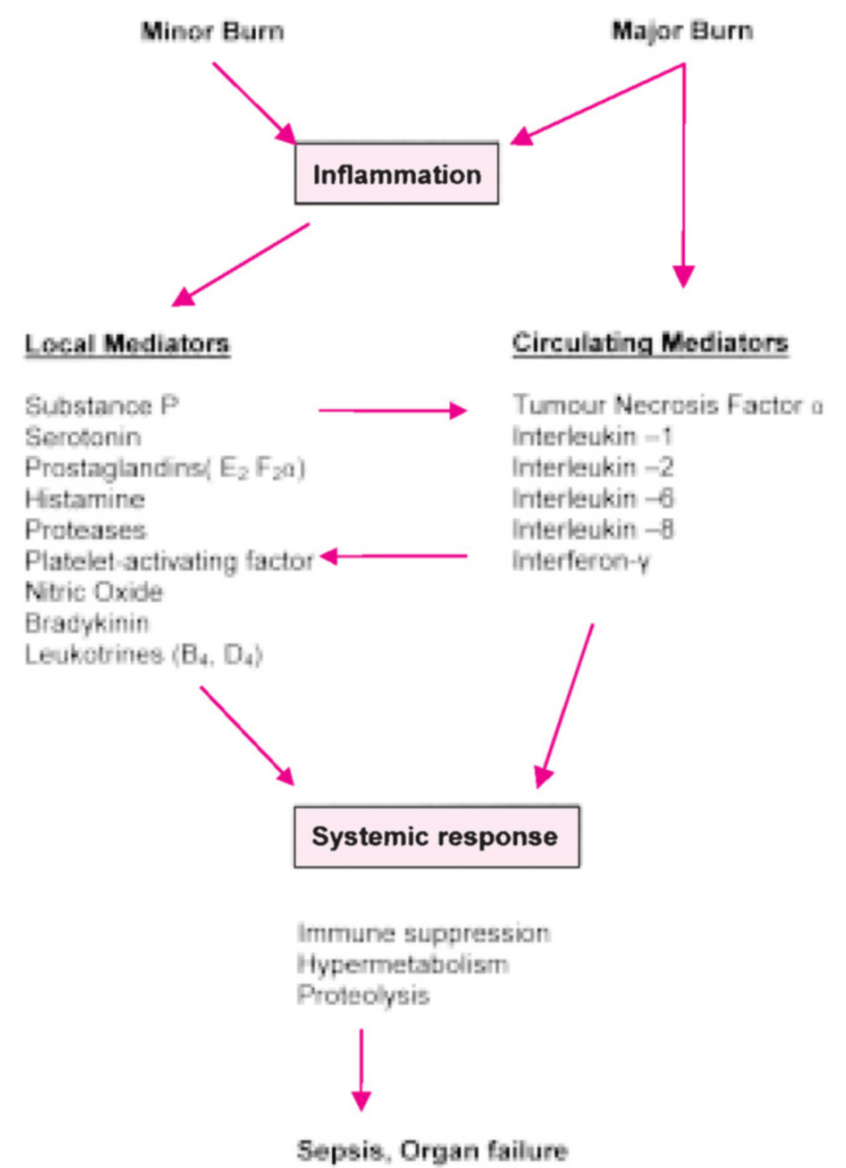

Fig. 1 : Pathophysiology of burn injury

The volumes required vary greatly, from a minimum of about $2 \mathrm{ml}$ per kilogram of body weight multiplied by the percentage of body-surface area burned during the first 24 hours to an amount that can exceed $6 \mathrm{ml}$ per kilogram multiplied by the percentage of body-surface area burned, with a mean of about $4 \mathrm{ml}$ per kilogram multiplied by the percentage of body-surface area burned [4]. Fluid requirements are greater if resuscitation has been delayed, in children with large burns, and in patients with smoke inhalation [5]. Large volumes are needed because only 20 to 30 percent of the crystalloid administered remains within the vascular system [6]. About half the fluid must be given during the first eight hours after the injury, coincident with the period of rapid edema formation. In most patients the hourly rate of urine flow, a reasonable indicator of organ perfusion, is the principal guide used to alter the rate of fluid administration. In adults, an hourly urine output of 0.5 $\mathrm{ml}$ per kilogram is adequate; in children who weigh less than $25 \mathrm{~kg}$, an output of $1.0 \mathrm{ml}$ per kilogram is necessary. Abrupt weight gains of 30 percent or more of body weight can result from resuscitation in patients with massive injury. Early endotracheal intubation and multiple limb and truncal escharotomies are commonly required in these circumstances. Pulmonary artery catheters are not routinely used but are helpful in elderly patients and in those with limited cardiac reserves.

The crystalloid requirement during the second day of treatment is about half that of the first day. Within 48 to 72 hours after the burn injury, the hematocrit begins a progressive fall due to such factors as intravascular resorption of edema, lysis of thermally injured cells, and the onset of the anaemia that is characteristic after burn injury. Crystalloid administration should be discontinued at the earliest possible time.

\section{Role of Colloid in resuscitation}

Use of colloid in burn shock has decreased, mainly because the controlled trials that have been done have shown no clear advantage to its use. Most centres defer colloid administration for 12 to 24 hours after the injury - a time when capillary permeability has partially returned to normal but plasma volume may be subnormal. Colloids are administered during $2^{\text {nd }} 24$ hours period at the rate of $0.3-0.5 \mathrm{ml}$ per $\mathrm{kg}$ of body weight per percentage of burns. Rest of the fluid requirement of $2^{\text {nd }} 24$ hours is met by adding salt free solution around $2000 \mathrm{ml}$ per 24 hours.

\section{Inhalation Injury}

Direct thermal injury below the larynx is rare because the humid airway gas transfers heat poorly. A variety of toxic incomplete products of combustion are inhaled. Carbon monoxide is commonly inhaled and thus can serve as a useful diagnostic marker. The airway mucosa becomes inflamed and usually contains carbon particles. Fiber optic laryngobronchoscopy is indicated if the diagnosis is in doubt. The incidence of inhalation injury increases with the increasing extent of the burn, so that it is present in two thirds of patients with flame burns that exceed 70 percent of the body-surface area and flame burns involving head and neck areas. Unless laryngeal edema is present, clinical evolution can require 12 to 24 hours or more as mucosal slough and secretions accumulate and airway obstruction and atelectasis progress. If signs of laryngeal edema appear hoarseness, brassy cough, or stridor - immediate endotracheal intubation is indicated. There is no method of quantitating the severity of injury, but measurement of arterial carboxyhemoglobin levels, extrapolated to the time of injury, provides a reasonable estimate of the severity of exposure. The simplest and probably the best treatment for carbon monoxide poisoning is ventilation with 100 percent oxygen, which decreases the half-life of carboxyhemoglobin from $41 / 4$ hours to about 50 minutes [7]. Inhalation injury is rarely limited to the upper airway and endotracheal intubation may be required for several days until edema subsides. In diffuse injury, airway infection is often severe or recurrent, but in less severe cases, healing occurs in about three weeks time. 
Corticosteroids and prophylactic antibiotics are ineffective [8].

\section{Burn-Wound Management}

\section{Topical Therapy}

Micro-organisms proliferate rapidly in burn wounds, especially in those severe enough to impair immune function. Topical antimicrobial agents have an important role. They delay the interval between injury and colonization and maintain low levels of the wound flora. Silver sulfadiazine is most widely antimicrobial agent used for routine prophylaxis because of its relatively low toxicity and ease of use. Treatment with silver sulfadiazine can cause leukopenia during the first week after injury, due in part to bone marrow toxicity, but it nearly always resolves within a period of several days despite continuation of the drug. A solution of 0.5 percent silver nitrate, although an effective antimicrobial agent, leaches electrolytes from open wounds and stains everything that it touches, hence it is not preferred.

\section{Care of Superficial Burns}

Superficial burns are treated with daily dressing and local wound care until epithelialization occurs. Full functional recovery is the rule. They can also be treated effectively by covering the denuded wound with a skin allograft or xenograft or one of several commercially available synthetic membranes [9]. If adherent, these materials reduce pain and eliminate the need for dressing changes with the patient under heavy sedation or general anesthesia, which may otherwise be necessary, especially in infants and children or uncooperative patients.

\section{Surgical Treatment of Deep Burns}

Full-thickness burns - those covering about 25 percent of the body - surface area or less in young or previously healthy patients - have a low mortality rate. Such injuries should be treated as soon after resuscitation as is feasible by tangential excision of the eschar and skin grafting. Sufficient autologous skin grafts should be available to close the wounds at the same operation, particularly if the grafts are meshed and expanded.

An experienced surgical and anaesthetic team and adequate amount of blood matched to the patient's blood type are essential.

Some deep partial - thickness burns are also treated surgically as soon as their depth can be estimated [10]. This approach results in better joint function and less severe hypertrophic scar than more conservative management, which requires a period of at least three weeks for wound epithelialization.

Grafting skin on established, granulating wounds from which the eschar has sloughed (a phenomenon due primarily to bacterial proteases) was once the norm, but it is currently the poorest surgical option. This approach is sometimes necessary, in the presence of severe illnesses or systemic complications.

\section{Treatment of Extensive Deep Burns}

For deep burns too extensive to be closed in one procedure, wound excisions can be staged - typically at intervals of about one week - as sufficient autologous skin grafts become available to close the excised wound. Alternatively, the burns can be completely excised within the first several days after injury and a temporary skin substitute used to close the wound remaining after all available autologous skin has been harvested and grafted. In severely burned children the systemic administration of recombinant human growth hormone can speed reepithelialization of skin - grafting sites and permit earlier reharvest [11].

\section{Newer concepts}

The skin substitute Integra [12] is a bilaminate membrane composed of a porous lattice of cross - linked chondroitin 6-sulfate engineered to induce neovascularization as it is biodegraded. An outer layer of silicone serves to close the wound while permitting water vapour transfer. This layer is peeled off after about 14 days and replaced with ultra thin $(0.01$ to $0.015 \mathrm{~cm} 4 /$ 1000 to $6 / 1000$ of an inch) autologous skin grafts. These donor sites can be reharvested after about one week.

Autologous keratinocytes cultured in vitro from a small $\left(2 \mathrm{~cm}^{2}\right)$ biopsy of unburned skin obtained shortly after injury offer another option for the treatment of extensive burns. Culture of the keratinocytes for three weeks results in multilayered epithelial sheets, which are then applied on freshly excised burns.

\section{References}

1. Brigham PA, McLaughlin E. Burn incidence and medical care use in the United States: estimate, trends, and data sources. J Burn Care Rehabil 1996; 17: 95-107.

2. Demling RH, Mazess RB, Witt RM, Wolberg WH. The study of burn wound edema using dichromatic absorptiometry. J Trauma 1978;18:124-8.

3. Arturson G. Pathophysiology of the burn wound and pharmacological treatment: The Rudi Hermans lecture, 1995. Burns 1996;22:255-74.

4. Baxter CR: Problems and complications of burn shock resuscitation. Surg Clin North Am 1978;58:1313-22.

5. Graves TA, Cioffi WG, McManus WF, Mason AD Jr, Pruitt BA Jr. Fluid resuscitation of infants and children with massive thermal injury. J Traums 1988;28:1656-9.

6. Sokawa J, Monafo WW, Deitz F,Flynn D. The relationship between experimental fluid therapy and wound edema in scald wounds. Ann Surg 1981;193:237-44. 
7. Smith G, Ledingham IM, Sharp GR, Norman JN, Bates EH. Treatment of coal gas poisoning with oxygen at 2 atmospheres pressure. Lancet 1962;1:816-9.

8. Levine BA, Petroff PA, Slade CL, Pruitt BA Jr. Prospective trials of dexamethasone and aerosolized gentamicin in the treatment of inhalation injury in the burned patient. J Trauma 1978;18:188-93.

9. Poulsen TD, Freund KG, Arendrup K, Nyhuus P, Pederson OD. Polyurethane film (Opsite) vs. impregnated gauze (Jelonet) in the treatment of outpatient burns: a prospective, randomized study. Burns 1991;17:59-61.
10. Engrav LH, Heimbach DM, Reus JL, Harnar TJ, Marvin JA. Early excision and grafting vs. non-operative treatment of burns of indeterminate depth: a randomized prospective study. J Trauma 1983;23:1001-4.

11. Gilpin DA, Barrow RE, Rutan RL, Broemeling L, Herndon DN. Recombinant human growth hormne accelerates wound healing in children with large cutaneous burns. Ann Surg 1994;220:19-24.

12. Heimbach D, Luterman A, Burke JF et al. Artificial dermis for major burns: a multi-centre randomized clinical trial. Ann Surg 1988;208:313-20.

\section{ANNOUNCEMENT BEST ARTICLE AWARD - MJAFI}

With effect from 1994 all Original Articles published in MJAFI are being screened for selection of the best two articles. These articles receive the 'Best Article Award' and the 'Second Best Article Award'. They carry a cash prize of Rs. 2000/- and Rs. 1000/- respectively to be shared by all authors. Articles are judged for their originality and research content.

So all those who believe that they have original work, not yet published, please send it in fast.

The following articles received the award for 2003 :

\section{Best Article Award}

Col Prakash Singh, Brig GS Misra, VSM, Col Amarjit Singh, Lt Col MGK Murthy (Retd) "Missile Injuries of Brain - an Experience in Northern Sector". MJAFI;2003;59(4):290-297.

\section{Second Best Article Award}

Lt Col JS Duggal, Lt Col V Jetley, Col Charanjit Singh, Lt Col SK Datta, Lt Col JS Sabharwal, Lt Col Sunil Sofat "Amplatzer Device Closure of Atrial Septal Defects and Patent Ductus Arteriosus : Initial Experience". MJAFI;2003; 59(3): 218-222. 